\title{
Gross and Clinical Anatomy of the Skull of Adult Chinkara (Gazella bennettii)
}

\author{
Salahud Din ${ }^{1, *}$, Saima Masood ${ }^{1}$, Hafsa Zaneb ${ }^{1}$, Habib ur Rehman², Saima Ashraf', \\ Imad Khan ${ }^{3}$, Muqader Shah ${ }^{4}$ and Syed Abdul Hadi ${ }^{1}$ \\ ${ }^{1}$ Department of Anatomy and Histology, University of Veterinary and Animal Sciences, Lahore \\ ${ }^{2}$ Department of Physiology, University of Veterinary and Animal Sciences, Lahore \\ ${ }^{3}$ College of Veterinary Sciences and Animal Husbandry, Abdul Wali Khan University, Mardan \\ ${ }^{4}$ Department of Animal Health, Faculty of Animal Husbandry and Veterinary Sciences, The \\ University of Agriculture, Peshawar
}

\begin{abstract}
A B S T R A C T
The objective of this study was (1) to study gross morphological, osteometric and clinical important landmarks in the skull of adult Chinkara to obtain baseline data and (2) to study sexual dimorphism in male and female adult Chinkara through osteometry. For this purpose, after performing postmortem examination, the carcass of adult Chinkara of known sex and age was buried in the locality of the Manglot Wildlife Park and Ungulate Breeding Centre, Nizampur, Pakistan, after a specific period of time the bones were unearthed. Gross morpohological features and various osteometric parameters of the skull were studied in the University of Veterinary and Animal Sciencies, Lahore, Pakistan. The shape of the Chinkara skull was elongated and had thirty two bones. The skull was comprised of the cranial and the facial part. The facial region of the skull was formed by maxilla, incisive, palatine, vomar, pterygoid, frontal, parietal, nasal, incisive, turbinates, mandible and hyoid apparatus. The bony region of the cranium of Chinkara was comprised of occipital, ethmoid, sphenoid, interparietal, parietal, temporal and frontal bone. The foramina identified in the facial region of the skull of Chinkara were, infraorbital, supraorbital foramen, lacrimal, sphenopalatine, maxillary and caudal palatine foramina. The foramina of the cranium of the Chinkara skull were the internal acoustic meatus, external acoustic meatus, hypoglossal canal, transverse canal, sphenorbital fissure, carotid canal, foramen magnum, stylomastoid foramen, foramen rotundum, foramen ovale and jugular foramen, and the rostral and the caudal foramina that formed the pterygoid canal. The measured craniometric parameters did not show statistically significant differences $(p>0.05)$ between male and female adult Chinkara except palatine bone, OI, DO, IOCDE, OCT, ICW, IPCW, and PCPL were significantly higher $(p>0.05)$ in male than female Chinkara and mean values of the mandibular parameters except $\mathrm{b}$ and $\mathrm{h}$ were significantly $(\mathrm{p}<0.5)$ higher in male than female Chinkara. Sexual dimorphism exist in some of the orbital and foramen magnum parameters, while high levels of sexual dimorphism identified in mandible. In conclusion, morphocraniometric studies of Chinkara skull made it possible to identify species specific skull and use clinical measurements during practical application.
\end{abstract}

\begin{tabular}{l} 
Article Information \\
\hline Received 07 February 2019 \\
Revised 23 May 2019 \\
Accepted 19 August 2019 \\
Available online 08 May 2020 \\
Authors' Contribution \\
\hline SD, SM and HZ conceived and \\
designed the experiments, interpreted \\
the data and wrote the article. HR, \\
SA, IK, MS and SAH helped in \\
preparation of the manuscript. \\
Key words \\
Chinkara, Skull, Morphology, \\
Morphometrics, Sexual dimorphism.
\end{tabular}

\section{INTRODUCTION}

$\mathrm{T}$ he Chinkara (Gazella bennettii) is an ungulate species of antelope innate of the Indian subcontinent, described by (Groves, 1969), as sandy or tawny coloured body; midface dark chestnut; ears are dark sandy grey; nosespot, if present, rather smudgy; light face-stripes off-white, not extending above eyes, dark ones deep red. Ear reaches about halfway towards muzzle. More heavily built: male weighs about $23 \mathrm{~kg}$, female $15-18 \mathrm{~kg}$, for a height of 58-61 cm (Mallon, 2008). Horns in male are rather straight, their tips slightly outturned, rings more prominent than in other species of this group; in female, fairly long and well-formed horns are present. They range

\footnotetext{
* Corresponding author: salahuddin7277@yahoo.com 0030-9923/2020/0005-1723 \$ 9.00/0

Copyright 2020 Zoological Society of Pakistan
}

up to 1500 meters altitude in Pakistan. They occupy Kavir national park in Iran (Mallon and Kingswood, 2001). In 2001, the population of Indian Chinkara was projected 0.1 million along with eighty thousand existing in the desert of Thar. While in Pakistan the population of Chinkara was dispersed and was lessened in the result of shooting. In Iran, the population of this species was disjointed. Among the wild ungulates of Pakistan, only the morphological and radiographic features of the tarsal bones are studied.

Von den Driesch (1976) published measuring point's guidelines to measure bone from sets (Plug, 2014) stated bone size measurements, in animals of similar size, often overlap, but the gross morphological features still differentiates between the species. Comparative skeletal gross anatomy and morphometry makes researchers to differentiate between closely related species (Brink, 2005). Animal gross morphological features show the significant dissimilarity with respect to age, breed, sex, environmental 
factors and nutritional condition among others. The measurements of these factors are important symbols for comparison. A lot of biometrical studies have been carried out in line to obtain a more objective genetic assessment, (Kunzel et al., 2003; Brombin et al., 2009). These metrical data are significant in anthropology (Bokonyi, 1974), regional anesthesiology (Olopade and Onwuka, 2005), taxonomy (Habel, 1982) and comparative gross anatomical and histological descriptions between and within breeds (Olopade et al., 2006). Bones can modify due to diverse lifestyles (Niven et al., 2004; Plug, 2014), which causes size modifications in a species (Soper, 2002). The skeletal system has been commonly used and still being using for the description of diverse species of animals, including humans (Guintard and Lallemand, 2003). This is because most of the parameters considered such as shape, height, length and size are easily accessible in the skeleton. On the basis of anatomical and osteometrical features species with distinct sexual dimorphism can be applied for estimation of sex ratio by sexing individual bones (Prummel and Frisch, 1986).

The head is a significant region for animals; therefore a gross morphological and radiographic investigation on the skull has been comprehensively studied. Most structures and vital organs as the brain, eyes, nose, tongue, ear, lips, horns, mouth and skull are located in the head region. Also, the health status of an animal depends on the normal functions of these vital organs (Olopade and Onwuka, 2003). The regional anatomy of the head region is needed for coordination, olfaction, deglutition and defiance of the body (Dyce et al., 2002; Olopade, 2003), particularly, the foramina in the skull bones are very helpful for clinical approach, surgical aspect and regional anesthesia. In the best of our knowledge, this was the first report on the morphology and regional clinical anatomy of the skull of adult Chinkara. Therefore, the aim of this study was planned to provide complete and comprehensive data on gross morphological, osteometric and clinical important landmarks in the skull of adult Chinkara to obtain baseline data and to study sexual dimorphisum in male and female adult Chinkara though osteometry.

\section{MATERIALS AND METHODS}

This study was assumed within the framework of $\mathrm{Ph}$. D. Research. The study samples were collected from the Manglot Wildlife Park and Ungulate breeding center Nizampur, KPK, Pakistan. Manglot Wildlife Park and Ungulate breeding center park spread over about 1,756 acres, a natural sanctuary for wildlife, were established in 1990 near the Indus River in Nizampur, Nowshera, Khyber
Pakhtunkhwa, Pakistan. The wild animals of the park include the Chinkara, hog deer, Black buck, Urial, Chital, common leopard, wolf, wild boar, jackal, porcupine and hare. The aims of this wildlife sanctuary are to conserve endangered species in a semi captive-breeding scheme like Chinkara, hog deer, Black buck, Urial and Chital and reintroductions of antelopes, when the population of these animals increases, into their former ranges to reverse the declining trend. In wild, wild life employees identify their presence through the presence and shape of fecal material. However, shape of fecal material modifies due to environmental conditions and thus specific species and sex identification impossible and to monitor the highest mortality rate in the form of male and female and type of wild herbivores. The skeletal remains are a main source for identification of an animal. In a wild environment their identification of their remains was difficult as the osteomorphological and osteometric features of these animals are not established. It is worthy to mention here, this area also provides grazing and browsing area for small ruminants and cattle. The Osseous remains of these antelopes are often encountered, but their specific identification poses considerable problems. To outcome this problem, this study was designed, Skull specimens were collected from 2014 to 2018 after natural mortality in a semi captive-breeding. The age and sex of the Chinkara were confirmed at the time of postmortem examination. After post mortem examination, skin was removed for stuffing purpose and the remaining carcass was buried in the park premises to obtain skull specimens. After elapse of 4 to 5 months specimens of the skull of each male and female Chinkara were unearthed. Subsequently, the specimens were put into clean, hot water for maceration and softening in a large aluminum container and were sundried subsequently for two to three days. After collection of all the required bones, they were kept in isolated boxes. The gross morphological and craniometric readings were measured according to (Von Den Driesch, 1976; Zedda et al., 2006; Chrószcz, 2007) at the University of Veterinary and Animal sciences, Lahore, Pakistan.

\section{Osteometric measurements}

The dimensions analyzed were:

\section{Skull parameters}

Skull length, Skull width, Skull/Cephalic index (SI $=$ Skull length $/$ Skull width $x$ 100) Supraorbital foramina distance, Distance between orbital rim to supraorbital foramina, Infraorbital foramina distance to orbit, Diameter of Infraorbital foramina, Distance from the process of the alveolar socket of canine tooth to the infraorbital canal, 
Infra-orbital canal to the root of alveolar tooth and between infraorbital foramina to the orbital rim (Figs. 1, 2).

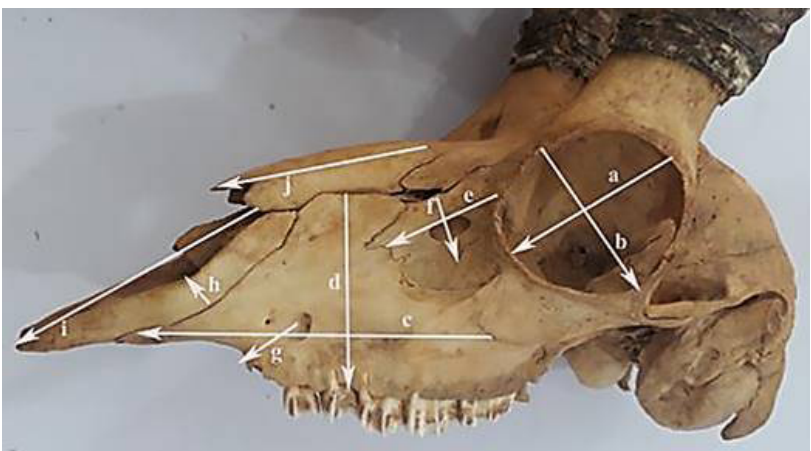

Fig. 1. Orbit length (a), orbital width (b), maxilla length (c) and width (d), lacrimal bone length (e), lacrimal bone width (f), infra-orbital canal to the root of alveolar tooth (g), incisive bone Width (h) incisive bone length (i) and nasal bone length (j).

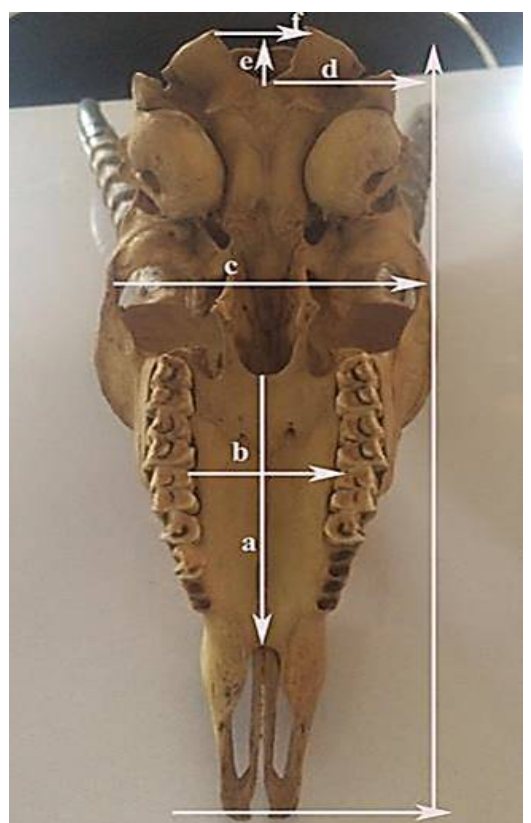

Fig. 2. Length of palatine bone (a), width of palatine bone (b), skull width (c) height of the foramen Magnum (e) and width of the foramen magnum (f).

\section{Orbital parameters}

Orbital parameters analyzed were (Fig. 1): orbit height (LO), orbit length (WO), orbital depth (DO), orbital index $(\mathrm{OI}=$ Orbital length / Orbital breadth $\mathrm{x} 100)$, interorbital interval at different points: i) at rostral extent. (IORE) ii) at central extent (IOCE) iii) at the caudal extent (IOCDE).

\section{Nasal parameters}

Length of nasal bone, width across nasal bone.

\section{Foramen Magnum parameters}

Foramen Magnum parameters analyzed were (Figs. 2, 3): height of the Foramen Magnum (FMH), width of the Foramen Magnum (FMW), Thickness of the occipital condyle (OCT), width of the intercondylar bones (ICW), width of the interparacondylar bones (IPCW), length of the paracondylar process (PCPL).

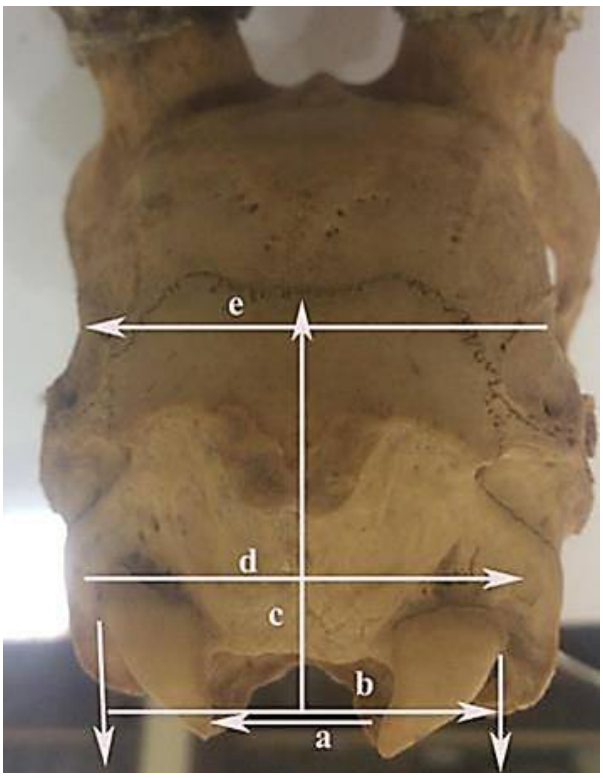

Fig. 3. Width of the foramen magnum (a), width of the Intercondylar bones (b), height of occipiatal bone (c) and width of occipital bone (d).

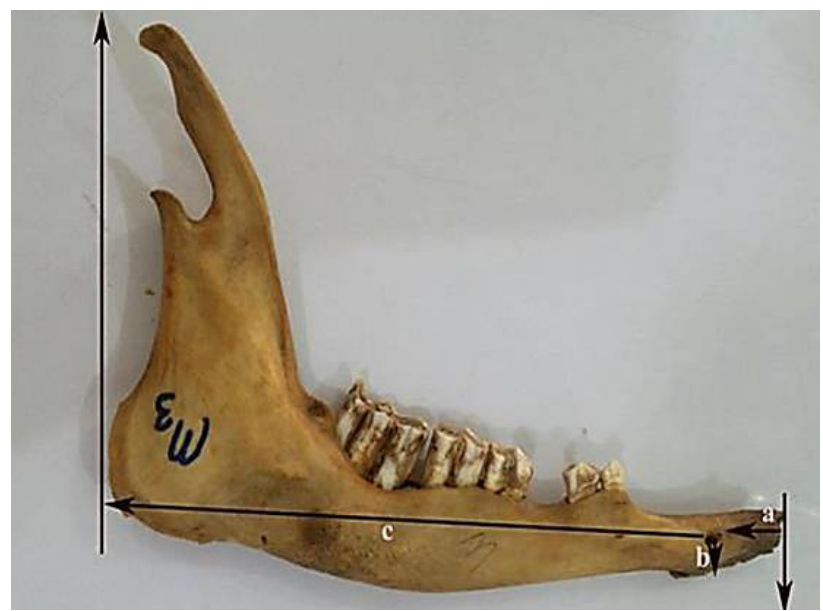

Fig. 4. Mandilbe of adult chinkara showing Interval from lateral alveolar root to the mental foramen (a), mental foramen (b) and space from mental foramen to the caudal mandibular border (c). 


\section{Mandibular parameters}

Mandibular parameters analyzed were (Figs. 4, 5): interval from lateral alveolar root to the mental foramen (a), distance between mental foramen and caudal mandibular border (b), mandibular length (c), distance between mandibular foramen to the base of the mandible (d), Space between the caudal border of mandible to below mandibular foramen (e), condyloid fossa to the height of the mandible (f), maximum mandibular height (g), condyloid fossa to the base of the mandible (h).

The measurements were repeated three times by two independent observers, and the mean values were recorded. The bones were described using the terminology given by World Association of Veterinary Anatomists (2012).

\section{Statistical design}

All anatomic values were expressed as the mean \pm standard deviation (SD) and means between male and female were compared with student t-test. Analysis of data was conducted with SPSS version 20.0 and differences were considered significant at $\mathrm{P}<0.05$.

\section{RESULTS}

In this section, we described the main features of the adult Chinkara skull collected from the same region and the entire studied specimens were fresh. This report at the best of our knowledge is first and the most comprehensive in the literature on the skull of adult Chinkara.

\section{External morphology of the skull}

The shape of the Chinkara skull was elongated and had thirty two bones. The skull was comprised of the cranial and the facial parts.

\section{The bones of the facial part of the skull}

This bony region of the skull was formed by maxilla and incisive (premaxilla) in lateral aspect, palatine, vomar and pterygoid in the ventral aspect, frontal, parietal, nasal and incisive bones in dorsal aspect, turbinates, mandible and hyoid apparatus in ventral aspect (Figs. 6, 7). The lower jaw (mandible) was articulated with the skull by synovial joints and all the remaining bones of the skull except the mandible were immovably firmly united with the help of sutures (suturae) joint. Moreover, the hard palate and choana were present on the ventral side of the skull (Fig. 7). The frontal bone had a prominent cornual process and extend caudal to the frontal process of the horns (Fig. 6), whereas, the dorsal surface of skull beyond the cornual process was formed by the parietal bone. The horizontal plate of the palatine bone was narrow and present on the ventral aspect (Fig. 7).

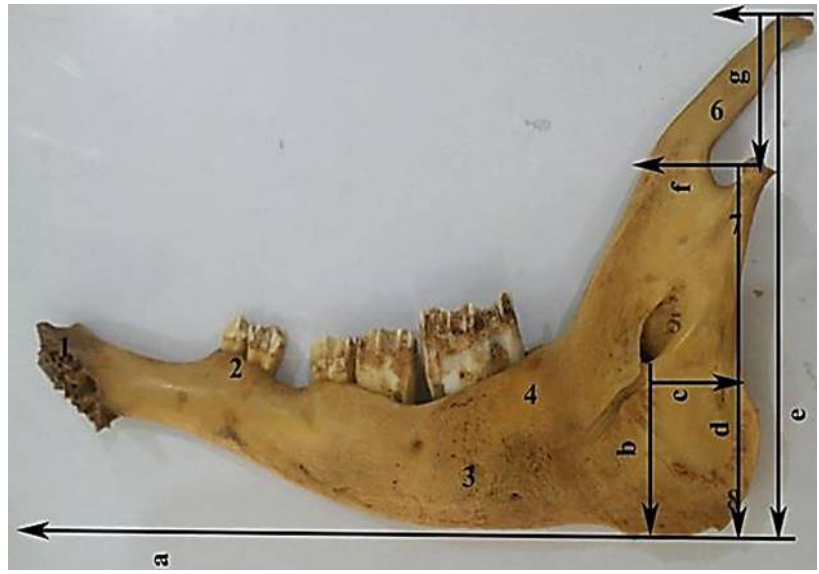

Fig. 5. Mandilbe of adult chinkara showing mandibular length (a), mandibular foramen to the base of mandible (b), caudal border of mandible to below mandibular foramen(c), condyloid fossa to the base of the mandible (d), condyloid fossa to the height of the mandible (g) and maximum mandibular height (e).

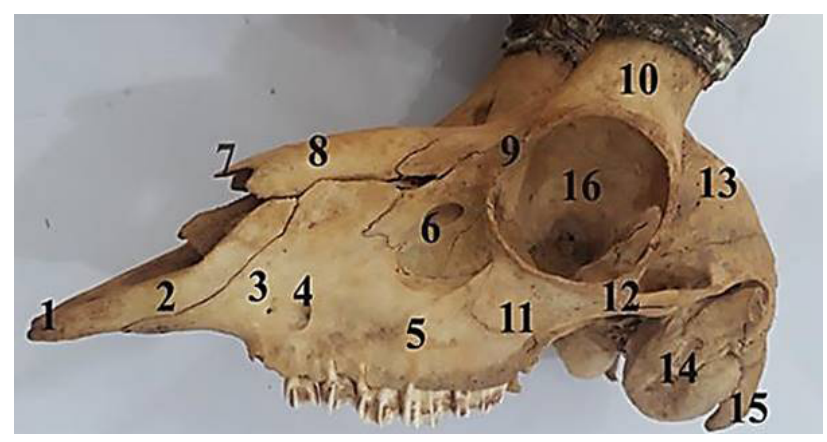

Fig. 6. Dorso-lateral view of the skull of male chinkara showing incisive bone (1), nasal process of incisive bone (2), maxilla bone (3), infraorbital foramen (4), parietal bone facial tuberosity (5), lacrimal (6), nasal process (7), nasal bone (8), orbital rim (9), cornual process of frontal bone (10), zygomatic bone (11), zygomatic arch (12), temporal fossa (13), tympanic bulle (14), paracondylar process (15) and orbit (16).

\section{The foramina of the facial region}

The foramina identified dorsally in the facial part of the skull of Chinkara were, the infraorbital, supraorbital and lacrimal foramina and rostrally maxillary, sphenopalatine and caudal palatine foramina, these rostral foramina were placed in the pterygopalatine fossa (Fig. 6).

The infra-orbital foramen was small, oval shaped, located in maxilla bone dorsally and oriented rostrally at the level of $2^{\text {nd }}$ cheek tooth (Fig. 6). The supraorbital foramen was positioned in the frontal bone in the supraorbital groove of the medial brim of the orbit (Fig. 6). The supra- 
orbital foramen penetrated the root of the zygomatic process and opened into the orbit. The ethmoidal foramen was positioned completely in the frontal bone and was located through the coincidence of the orbital ramus of frontal bone and presphenoid wing of the spheniod bone. The diameter of ethmoidal foramen was smaller than optic foramen and orbitorotundum. The orbit through ethmoidal foramen, optic foramen and foramen orbitorotundum linked with the cranial cavity. The round foramen and orbital fissure unite to form foramen orbitorotundum. The minor palatine foramens were present completely on the horizontal process of the palatine bone while the major palatine foramina were located on the intersection of horizontal plate of palatine bone and the palatine process of maxilla (Fig. 7).

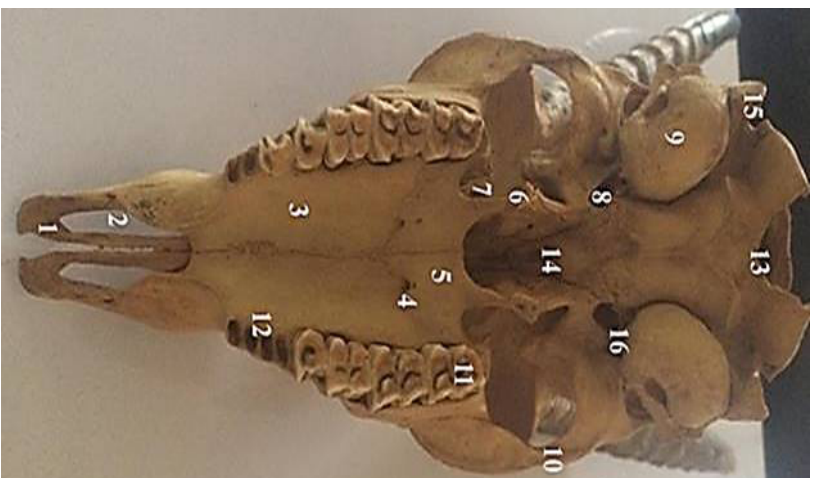

Fig. 7. Ventral view of the chinkara skull showing incisive bone (1), palatine fissure (2), maxillary process of palatine bone (3), major palatine foramen(4), horizontal palate of palatine bone (5), hamalus of pteygoid bone (6), sphenoid of palatine bone (7), oval foramen (8), tympanic bulla (9), zygomatic arch (10), molar bone (11), alveoli (12) foramen magnum (13), vomar bone (14), paracondylar process(15) and muscular process (16).

\section{The bones of the cranial region}

The bony region of the cranium of Chinkara was comprised of sphenoid, occipital, ethmoid, parietal, interparietal, temporal and frontal bone (Figs. 6, 7, 8). The occipital bone consisted of two occipital condyles and formed the ventral part of the nuchal surface (Fig. 8) and nuchal crest. The temporal bone also contributed in the formation of the nuchal crest, lateral to the paramastoid process (Fig. 9). The paramastoid processes were thin, prismatic shaped and had projected ventrally (Figs. 6, $7,8)$. The ethmoid bone was wedged between the nasal and cranial cavity. the ethmoid bone was sutured with the presphenoid caudally, with vomer and palatine rostroventrally and with the frontal bones dorso-rostrally (Figs. 6, 7). The parietal bone enters into the formation of the roof of the cranial cavity and its dorsal part formed the extension of the frontal sinus.

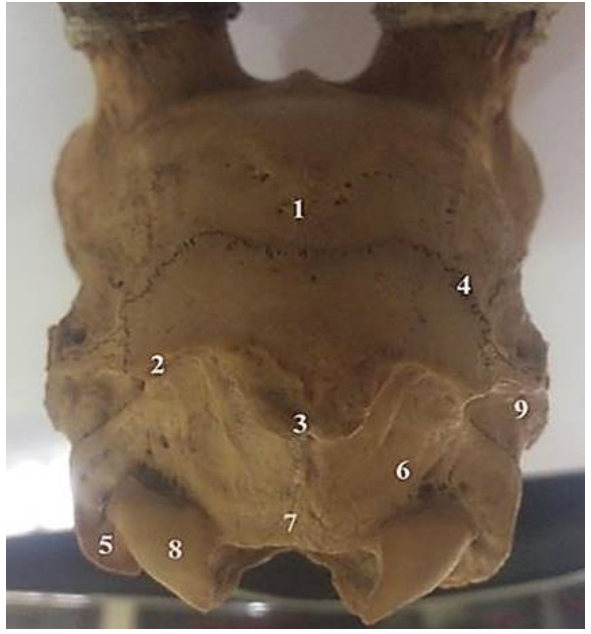

Fig. 8. Caudal view of the chinkara skull showing parietal bone (1), nuchal crest (2), external occipital protruberance (3), zig zag suture joint (4), paracondylar process (5), lateral part of the occipital bone (6), occipital crest (7), occipital condyle (8) and mastoid process (9).

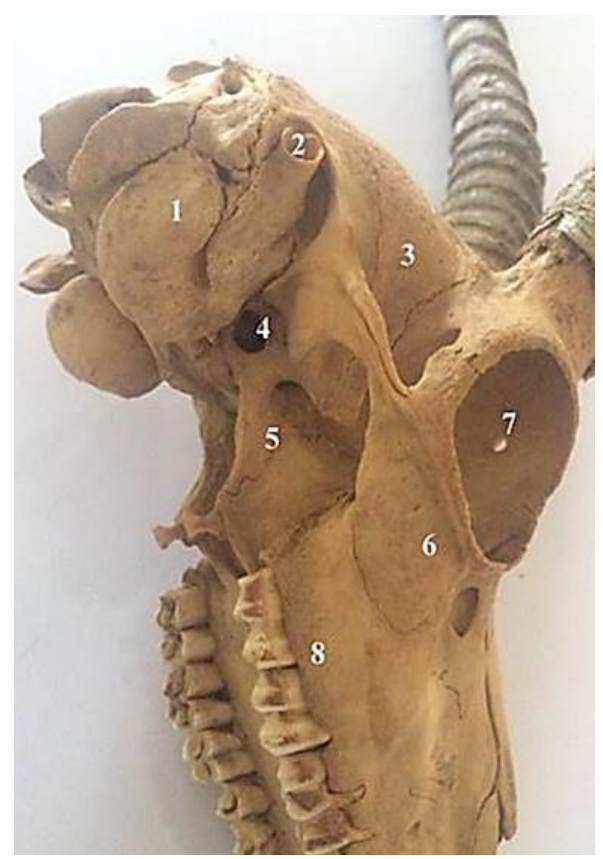

Fig. 9. Lateral view of the chinkara skull showing tympanic bulla (1), external acoustic meatus (2), temporal fossa (3), oval foramen (4), spheniod bone (5), orbit (7) and alveolar border (8)

Orbit

The orbits were oval in shape, complete, formed by the zygomatic, frontal, and lacrimal bone and placed rostro-laterally; the highest share in the development of the bony orbit was predominantly by the frontal bones 
tailed by the zygomatic and the lacrimal. The orbital rim was nearly circular in shape (Figs. 6,9).

\section{The foramina of the cranial region}

The foramina of the cranial region of the skull of the Chinkara were the internal acoustic meatus, external acoustic meatus, hypoglossal canal, transverse canal foramen, sphenorbital fissure, carotid canal, foramen magnum, stylomastoid foramen, foramen ovale, foramen rotundum and jugular foramen, and the caudal and the rostral foramina that molded to form pterygoid canal. The foramen magnum (foramen occipital magnum) was large and roughly oval in shaped (Figs. 7, 8). The oval foramen was present in the sphenoid bone. The ventral surface (Figs. 7, 9) of the skull had foramen oval and present entirely in the sphenoid bone.

\section{Gross morphology of the mandible}

In the present study, it was observed that the mandibular symphysis (Fig. 10) remained unossified in adult Chinkara. Slightly lateral curvedness was noted in the distal portion of the ramus (pars molaris) of the mandible of Chinkara. It was noted that the rostral (incisive) region of the body of mandible remains elevated from the ground surface in Chinkara. The alveolar border (limbus alveolaris) of the incisive part had three alveoli for incisor teeth and one for canine on each side in adult Chinkara (Fig. 11). The molar region of the body had alveoli for six cheek teeth (three premolar and three molar teeth) and for each cheek teeth two alveoli were observed except last cheek teeth had three alveoli in Chinkara (Fig. 10). On lateral surface (Fig. 11) merely one mental foramen (foramen mentale) caudal to the base of the incisor tooth, was notified. The mandibular tuberosity (Fig. 11) was observed on the lateral surface slightly caudal and distal to last molar teeth in Chinkara. In adult Chinkara, the ventral border of the body of the mandible was thick, smooth and convex in length (Fig. 11). The caudal and perpendicular part of the mandible (ramus), was the non-tooth bearer part (Fig. 10). The dorsal articular surface (caudal extremity) was comprised of the coronoid process and the condylar process with the paramount notch. The coronoid process of the ramus forms the highest point of the bone (Fig. 11).

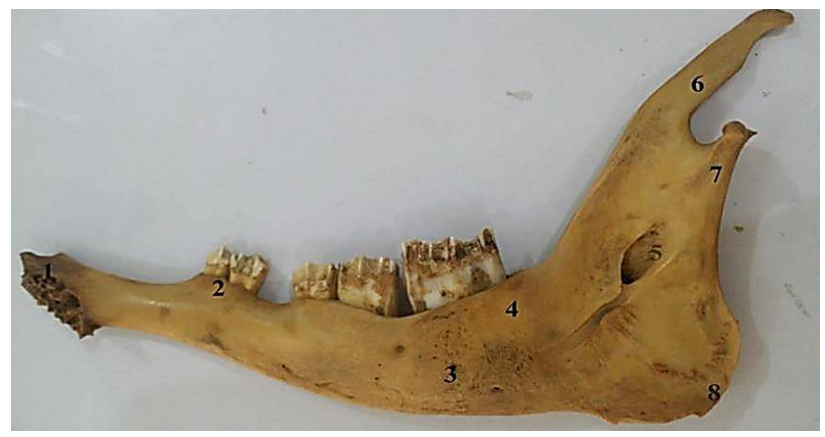

Fig. 10. Medial view of the mandible of adult Chinkara showing alveolar sockets for incisors (1), first premolar (2), molar (4), mandibular foramen (5), coronoid process (6) and posterior border of ramus (7).

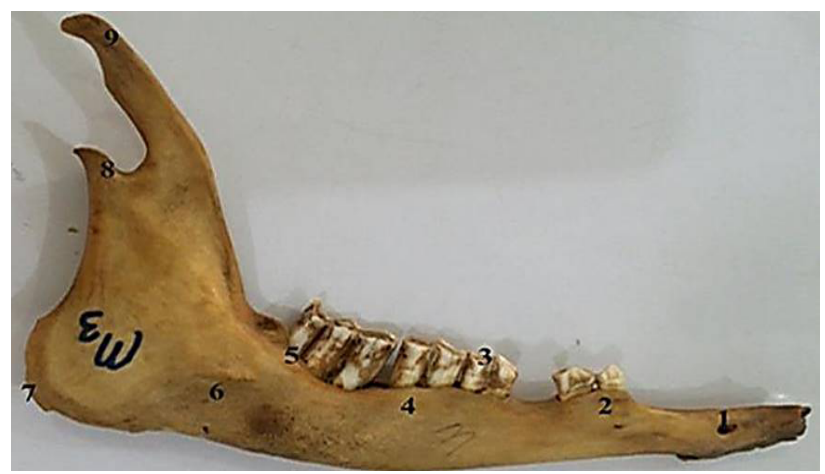

Fig. 11. Lateral view of the mandible of adult Chinkara showing mental foramen (1), first premolar (2), premolar $(3,4)$, molar (5), mandibular tuberosity (6), mandibular angle (7), coronoid process (8) and condylar process (9).

Table I.- Measurements $(\mathrm{cm}, \mathrm{Mean} \pm \mathrm{SD})$ of skull parameters of adult Chinkara based on sex.

\begin{tabular}{lccc}
\hline & Male & Female & P-value \\
\hline Skull length & $21.65 \pm 0.14$ & $19.22 \pm 0.11$ & 0.38 \\
Skull width & $7.64 \pm 0.54$ & $7.59 \pm 0.52$ & 0.91 \\
Skull/Cephalic index & $35.26 \pm 0.05$ & $39.49 \pm 0.09$ & 0.64 \\
Supraorbital foramina distance & $3.31 \pm 0.10$ & $3.35 \pm 0.94$ & 0.05 \\
Distance between orbital rim to supraorbital foramina & $1.72 \pm 0.07$ & $1.50 \pm 0.04$ & 0.14 \\
Infraorbital foramina distance to orbit & $4.45 \pm 0.05$ & $4.12 \pm 0.04$ & 0.82 \\
Diameter of Infraorbital foramina & $0.53 \pm 0.06$ & $0.39 \pm 0.02$ & 0.008 \\
Infra-orbital canal to the root of alveolar tooth & $1.36 \pm 0.06$ & $0.96 \pm 0.09$ & 0.05 \\
between Infraorbital foramina to rim & $3.10 \pm 0.14$ & $3.05 \pm 0.15$ & 0.96 \\
\hline
\end{tabular}


Table II.- Measurements (cm, Mean \pm SD) of orbital and foramen magnum parameters of the skull of male and female adult Chinkara.

\begin{tabular}{lccc}
\hline & Male & Female & P-value \\
\hline Lo & $3.77 \pm 0.12$ & $3.64 \pm 0.08$ & 0.29 \\
Wo & $3.42 \pm 0.11$ & $3.29 \pm 0.08$ & 0.36 \\
OI & $90.84 \pm 0.12$ & $90.16 \pm 0.10$ & 0.05 \\
Do & $2.34 \pm 0.18$ & $2.41 \pm 0.06$ & 0.01 \\
IORE & $5.80 \pm 0.10$ & $5.34 \pm 0.09$ & 0.71 \\
IOCE & $5.44 \pm 0.42$ & $4.51 \pm 0.96$ & 0.25 \\
IOCDE & $8.25 \pm 0.62$ & $7.31 \pm 0.16$ & 0.00 \\
FMH & $1.65 \pm 0.04$ & $1.49 \pm 0.07$ & 0.12 \\
FMW & $1.75 \pm 0.11$ & $1.79 \pm 0.05$ & 0.15 \\
FMI & $89.64 \pm 0.04$ & $87.19 \pm 0.04$ & 0.20 \\
OCT & $1.52 \pm 0.17$ & $1.28 \pm 0.05$ & 0.05 \\
ICW & $4.46 \pm 0.20$ & $3.96 \pm 0.08$ & 0.04 \\
IPCW & $4.73 \pm 0.09$ & $4.31 \pm 2.19$ & 0.03 \\
PCPL & $2.70 \pm 0.27$ & $1.95 \pm 0.05$ & 0.001 \\
\hline
\end{tabular}

Orbit height (Lo), Orbit length (WO), Orbital index (OI), Orbital depth (Do), Interorbital interval at different points: i) at rostral extent. (IORE) ii) at central extent (IOCE) iii) at caudal extent (IOCDE). Height of the Foramen Magnum (FMH), Width of the Foramen Magnum (FMW), Index of foramen magnum (FMI), Thickness of the Occipital Condyle (OCT), Width of the Intercondylar bones (ICW), Width of the Interparacondylar bones (IPCW), Length of the Paracondylar Process (PCPL).

Table III.- Measurements ( $\mathrm{cm}, \mathrm{Mean} \pm \mathrm{SD}$ ) of the facial bones of the skull of male and female adult Chinkara $(\mathrm{n}=\mathbf{2 0})$.

\begin{tabular}{llccc}
\hline \multicolumn{2}{l}{ Facial bones } & Male & Female & P-value \\
\hline Maxilla & Lma & $1.25 \pm 0.12$ & $1.40 \pm 0.05$ & 0.09 \\
& Wm & $1.47 \pm 0.16$ & $1.69 \pm 0.05$ & 0.08 \\
Premaxilla & Lpm & $6.11 \pm 0.10$ & $5.09 \pm 0.14$ & 0.76 \\
& Wpm & $3.77 \pm 0.08$ & $3.23 \pm 0.06$ & 0.80 \\
Lacrimal & Lla & $1.25 \pm 0.12$ & $1.40 \pm 0.05$ & 0.04 \\
& Wla & $1.47 \pm 0.16$ & $1.69 \pm 0.05$ & 0.08 \\
Nasal & Lna & $5.96 \pm 0.22$ & $5.90 \pm 0.34$ & 0.52 \\
& Wna & $1.41 \pm 0.06$ & $1.30 \pm 0.07$ & 0.39 \\
Palatine & Lpa & $10.58 \pm 0.60$ & $9.16 \pm 0.24$ & 0.00 \\
& Wpa & $2.83 \pm 0.22$ & $2.67 \pm 0.10$ & 0.01 \\
\hline
\end{tabular}

Length (Lma), Width (Wma), Length (Lpm), Width (Wpm), Length (Lla), Width (Wla), length (Lna), width (Wna), length (Lpa),Width (Wpa).

\section{Descriptive studies}

Various skull and mandibular parameters of both adult male and female Chinkara calculated were tabulated in Tables I, II, III and IV. Measurements of the facial bones of the skull of male and female adult Chinkara were tabulated in Table III. The measured parameters did not show statistically significant differences $(p>0.05)$ between male and female adult Chinkara except palatine bone. Various orbital parameters have been summarized in Table II. Descriptive statistics of the measured orbital parameters did not show statistically significant differences $(\mathrm{p}>0.05)$ between male and female adult Chinkara except Orbital Index (OI), Orbital depth (Do) and the Interorbital interval at the caudal extent (IOCDE). Foramen magnum parameters measured for male and female adult Chinkara were tabulated in Table II. The average mandibular values obtained in the current study were presented in Table IV. Mean values of the mandibular parameters except $b$ and $\mathrm{h}$ were significantly $(\mathrm{p}<0.5)$ higher in male than female Chinkara.

Table IV.- Measurements $(\mathrm{cm}, M e a n \pm S D)$ of the mandible of adult Chinkara $(n=20)$.

\begin{tabular}{cccc}
\hline & Male & Female & LVS \\
\hline $\mathrm{a}$ & $1.58 \pm 0.29$ & $1.25 \pm 0.19$ & 0.03 \\
$\mathrm{~b}$ & $12.03 \pm 0.24$ & $11.44 \pm 0.13$ & 0.09 \\
$\mathrm{c}$ & $14.18 \pm 0.48$ & $12.93 \pm 0.96$ & 0.00 \\
$\mathrm{~d}$ & $2.66 \pm 0.18$ & $2.39 \pm 0.05$ & 0.00 \\
$\mathrm{e}$ & $1.54 \pm 0.08$ & $1.60 \pm 0.14$ & 0.00 \\
$\mathrm{f}$ & $2.62 \pm 0.05$ & $2.38 \pm 0.23$ & 0.00 \\
$\mathrm{~g}$ & $8.21 \pm 0.33$ & $7.33 \pm 0.50$ & 0.01 \\
$\mathrm{~h}$ & $5.75 \pm 0.25$ & $5.27 \pm 0.27$ & 0.67 \\
\hline
\end{tabular}

Lateral alveolar root to the mental foramen (a), mental foramen to the caudal mandibular border (b) Mandibular length (c) Mandibular foramen to base of mandible (d) Caudal border of mandible to below mandibular foramen (e) Condyloid fossa to the height of the mandible (f) Maximum mandibular height (g) Condyloid fossa to the base of the mandible (h).

\section{DISCUSSION}

Literature on the gross morphological and osteometric descriptions of the skull of the Chinkara was not available. Morphological and morphometrical studies of the skeletal elements are used for assessment of animals' age, identification of species, genetic and forensic exploration. In mammals, the skull is highly conservative, informative and adaptive structures, symbolized the most influential tool for biogeographic, phylogenetic and systematic studies afore the molecular investigations (Loy, 2007). In animals, specific parts of the skeletal system are often implied as reflective catalogues to define bodily proportions, physiological growth and confrontation to seasonal variations in food availability (Zanneśe et al., 2006b). Different researchers described the shape of the skull in different animals. In this research, the skull of adult Chinkara was elongated in shape analogous shape 
was narrated (Sarma, 2006) in kagani goat, (Ramswarup, 2011) in chital and (Choudhary et al., 2015) in blackbuck. While, in camels (Shahid and Kausar, 2005) reported that the skull was pentagonal in outline.

The shape and location of the infra-orbital foramen and supraorbital foramen described in this study as in accordance to the observations (Parmar and Shrivastava, 2003) in chital and (Choudhary et al., 2015) in blackbuck, and (Bharti, 2016) in blue bull; whereas this study opposes the reports of (Nickel et al., 1973), in dog (Smuts and Bezuidenhout, 1987) in camel.

The orbital shape of an animal defines the degree of visual field and the amount of shield gave to the eye and its contiguous tissue (Dyce et al., 2002). The gross morphology of the orbits of adult Chinkara was parallel to the reports of Sharma (2006) in Kagani goat and Choudhary et al. (2015) in blackbuck, while, contradiction to the current study was seen in reports of Taluja et al. (2000) in tiger, Getty (1975) in horse, Karimi et al. (2011) in Mehraban sheep and Prince et al. (1960) in dogs.

The size, shape and location of the foramina identified in the facial region of the skull of Chinkara were analogous to reports of Parmar and Shrivastava (2003) and Choudhary et al. (2015) in blackbuck and Bharti (2016) in chital deer, but these conclusions were in disagreement with the findings of Smuts and Bezuidenhout (1987) in camel, and Joshi (2004) in tiger.

Craniometric dimensions are used for the identification of species and finding of intraspecies variations (Yalçin and Kaya, 2009; Karimi et al., 2011; Sheremetyeva and Sheremetyev, 2008). The measured parameters of the facial bones of the skull did not show statistically significant differences $(p>0.05)$ between male and female adult Chinkara except Palatine bone, which was in accordance with the findings in most of the craniometric dimensions in the Pyrenean chamois (Garcia-Gonzalez and Barandalla, 2002), in adult camels (Yahaya et al., 2012) and the goats found in the middle regions of Nigeria (Samuel et al., 2013), in which no marked sexual dimorphism was observed in most of the skull indices measured. In the present research, the skull length, skull width, and cephalic index were measured. Getty (1975) classical anatomist and Dyce et al. (2002) did not cite the measurements, they described the skull bones just morphologically in domestic animals, while, Yahaya et al. (2012) and Monfared (2013) cited that in camel. Cephalic/ skull index is an essential parameter in forensic medicine, anthropology and gender determinations (Lakshmi et al., 2015). Cephalic/skull index calculated in the current study in male and female adult Chinkara was $35.26 \pm 0.05$ and $39.49 \pm 0.09$, respectively, however, higher value of the skull index $66.05 \pm 0.05$, $52.76 \pm 1.13$ and $59.00 \pm 0.11 \mathrm{~cm}$ were reported in blue bull (Bharti, 2016), in Mehraban sheep (Karimi et al., 2011) and in blackbuck (Choudhary et al., 2015), respectively. The low skull index in the current investigation indicated the shape of the Chinkara skull was dolichocephalic, these findings were in line with the findings (Ramswarup, 2011) in chital, (Choudhary et al., 2015) in blackbuck and (Bharti, 2016) in blue bull, contrary to the current study, it was reported brachycephalic (Joshi, 2004) in tiger and mesaticephalic (Lieve et al., 2003) in dog. The cephalic/ skull index described in this study, was on the basis of international anatomical description, depending upon this index, types of head shapes are: dolichocephalic $(<75)$, mesaticephalic ( 75 to 83 ) and brachycephalic( $>83)$. The current study was in agreement to the reports of (Aragon et al., 1998) who reported that animals feed on woody shrubberies have shorter and broader crania than animals that feed mostly on herbaceous plants.

In the current study, no bilateral variations were found in orbital parameters. These findings were consistent with the study of Olopade et al. (2011) in Nigerian local pig, however, in contrast to the studies of Choudhary et al. (2015) in blackbuck and Sarma (2006) in Kagani goat who notified bilateral variations in orbital parameters. Black buck and Chinkara are related wild ungulates, the difference observed in orbital parameters are highly important during practical approach. In the current study, mean of the right and left of all the orbital parameters was used as a measurement value in all statistical calculations, since no statistically significant difference ( $p>0.05$ ) was found between the osteometric values. The orbital parameters had clinical importance is to ascertain the topographic anatomy, in order to perform surgical procedures in the area of the head, e.g. ophthalamectomy, dehorning and eyelid droopy (Allouch, 2008). A higher orbital index from the current study was reported in Blue bull (Bharti, 2016) and in tiger (Taluja et al., 2000), which was $111.93 \pm 0.38$ and 155 , respectively. However, lower orbital index of $21.46 \pm 0.68 \mathrm{~cm}$ described by Karimi et al. (2011) in Mehraban sheep.

This study was novel in Chinkara, sexual dimorphism based on craniometric data was not yet reported in the literature. The measured anatomical standards were of clinical importance and aid in regional nerve blocks of mental and infraorbital nerves and hence it was ascertained in the current study to adopt the same approach to access cranial nerves in both sexes of adult Chinkara. Good information about the location of the foramen and the infraorbital nerve can offer a harmless clinical procedure, such as a surgical procedure, the practice of intra and extra oral anesthesia (Mozsary and Middleton, 1983; Lawrence and Poole, 1992; Zide and Swift, 1998). These conclusions in this study were of great clinical implication in relation to the infra-orbital nerve block. The injection of a local anesthetic agent through the infra-orbital foramen leads 
to the analgesia of the incisor, canine and the first two premolar teeth (Hall et al., 2000). This data will corroborate to the regional anesthesia of the areas innervated by the infra-orbital nerve in the adult Chinkara.

The data created from above mentioned parameters were not reported already, in this species, which had great clinical significance and may be used as a landmark for tracing the infra-orbital nerve, mental nerve and mandibular nerve desirable for its desensitization during any type of procedures at the level of the foramen.

In addition to species comparison, many researchers underlined the usefulness of foramen magnum diameter in differentiation of sex within the species (Göçmez et al., 2014; İlgüy, 2014; Simoens, 1994; Uthmanet et al., 2012) which is of high significance in forensic investigations. Among the seven parameters measured in the current investigations of the foramen magnum OCT, ICW, IPCW, and PCPL were significantly higher $(p>0.05)$ in male than female Chinkara. These measurements may be used for sexual dimorphism in Chinkara, along with other skull parameters identified in the current study. The height and width of the foramen magnum of the adult Chinkara measured in the current study were lower than shown in blackbuck (Choudhary et al., 2015) and in blue bull (Bharti, 2016). From this study, it may be proposed a divergence in morphology, like other measurements, the foramen magnum height and width showed variation from the other related wild ungulates.

In our study, mean values of the mandibular parameters except $b$ and $h$ were significantly $(p<0.5)$ higher in male Chinkara than female Chinkara. Similar to foramen magnum parameters, sexual dimorphism was more evident in mandibular parameters. Sexual dimorphism in closely related animals viz Black Buck, Chital, Hog deer, Urial and Blue Bull were still not specified. However, mandibular parameters studied in our study were lower than reported in blackbuck (Choudhary et al., 2015), in blue bull (Bharti, 2016) and in Iranian native cattle (Monfared, 2013).

\section{CONCLUSIONS}

No previous information on gross morphological and osteometric data on the skull and mandible of Chinkara deer were available, so the current study provides primary baseline data, we therefore consider that the data presented above will form vital standard for use by clinician working on wild animals and baseline for further research work and a good initiation for further interdisciplinary professional and scientific researchers (anatomists, archeozoologists, biologists, hunters, forensic scientists). The overall gross morphological and osteometric data obtained data showed similarities with others domestic mammals, but also several peculiarities in the Chinkara head osteology.
Furthermore, in this research, osteometrical data derived was from modern populations are helpful as can be compared with ancient animal populations in archaeozoological assessments. However, this study describes an important preliminary step, more data regarding different age group and in different environmental condition and to include other species of game and protected mammals should be assembled; these will prove valuable in other research studies on deer metrics.

\section{ACKNOWLEDGEMENTS}

The authors are thankful to the Chief Conservator Wildlife and Conservator (WL), Wildlife Department, Khyber Pakhtunkhwa and the Divisional Forest Officer, Peshawar Wildlife Division, for providing essential facilities for the present research.

\section{Statement of conflict of interest}

The authors have declared no conflict of interest.

\section{REFERENCES}

Allouch, G., 2008. Textbook of comparative anatomy: The bones, ligaments and joints. Veterinary Medicine Collage, Al-Baath University, DamascusAleppo Highway, Homs», Syria, pp. 329, 334, 356, 363-366, 377.

Bharti, S.K., 2016. Osteo-morphological studies on the skull and appendicular skeleton of blue bull (Boselaphus tragocamelus). Phd thesis, G.B. Pant University of Agriculture and Technology, Pantnagar, Uttarakhand, India.

Brink, J.S., 2005. The evolution of the black wildebeest, Connochaetes gnou, and modern large mammal faunas in central southern Africa. D Phil. dissertation, University of Stellenbosch, Stellenbosch, South Africa.

Brombin, C., Mo, G., Zotti, A., Giurisato. M., Salmaso, L. and Cozzi, B., 2009. A landmark analysis based approach to age and sex classification of the skull of the Mediterranean monk seal Monachus monachus, Hermann, 1779. Anat. Histol. Embryol., 38: $\quad 382-386 . \quad$ https://doi.org/10.1111/j.14390264.2009.00958.x

Choudhary, O.P., Ishwer Singh Bharti, S.K., Mohd, K.I., Dhote, B.S. and Mrigesh, M., 2015. Clinical anatomy of the head region of the black (Antelope cervicapra). Indian Vet. J., 92: 59-62.

Chrószcz, A., Janeczek, M., Onar, V., Pazvant, G. and Pospieszny, N., 2007. The shoulder height estimation in dogs based on the internal dimension of cranial cavity using mathematical formula. 
Anat. Histol. Embryol., 36: 269-271. https://doi. org/10.1111/j.1439-0264.2007.00760.x

Dyce, K.M., Sack, W.O. and Wensing C.J.G., 2002. Textbook of veterinary anatomy, $3^{\text {rd }}$ edn. WB Saunders, Philadelphia.

Garcia-Gonzalez, R. and Barandalla, I., 2002. Sexual dimorphism of phyrenean chamois based on skull morphometry. Pirinious, 157: 25-37. https://doi. org/10.3989/pirineos.2002.v157.58

Getty, R., 1975. Equine and ruminant osteology. In: Sisson and Grossman's, the anatomy of the domestic animals (ed. R. Getty), Vol. I, $5^{\text {th }}$ edn. W.B. Saunders Company, Philadelphia, pp. 273317, 318-348, 1231-1252.

Göçmez, C., Göya, C., Hamidi, C., Kamaşak, K., Yilmaz, T., Turan, Y., Uzar, E. and Ceviz, A., 2014. Threedimensional analysis of Foramen Magnum and its adjacent structures. J. Craniofac. Surg., 25: 93-97. https://doi.org/10.1097/SCS.0b013e3182a2ea10

Groves, C.P., 1969. On the smaller gazelles of the genus Gazella de Blainville, 1816. Z. Saugetierk., 34: 3860.

Guintard, C. and Lallemand, M., 2003. Osteometric study of metapodial bones in sheep (Ovis aries, L. 1758). Ann. Anat., 185: 573-583. https://doi. org/10.1016/S0940-9602(03)80131-0

Habel, R.E., 1982. Ruminant introduction. In: In: Sisson and Grossman's, the anatomy of the domestic animals (ed. R. Getty). W.B. Saunders Company, Philadelphia, pp. 821-822.

Hall, L.W., Clarke, K.W. and Trim, C.M., 2000. Wright's veterinary anaesthesia and analgesia, $10^{\text {th }}$ edn. ELBS and Baillierre Tindall, London.

İlgüy, D., İlgüy, M., Ersan, N., Dölekoğlu, S. and Fişekçioğlu, E., 2014. Measurements of the foramen magnum and mandible in relation to sex using CBCT. J. Foren. Sci., 59: 601-605. https:// doi.org/10.1111/1556-4029.12376

Joshi, H., 2004. Gross anatomical studies of the skull of Indian tiger (Panthera tigris). M.V.Sc. thesis, Rajasthan Agricultural University, Bikaner, Rajasthan.

Karimi, I., Onar, V., Pazvant, G., Hadipour, M. and Mazaheri, Y., 2011. The cranial morphometric and morphologic characteristics of Mehraban sheep in Western Iran. Glob. Vet., 6: 111-117.

Kunzel, W., Breit, S. and Oppel, M., 2003. Morphometric investigation of breed specific features in feline skulls andconsiderations on their functional implications. Anat. Histol. Embryol., 32: 218-223. https://doi.org/10.1046/j.1439-0264.2003.00448.x

Lakshmi, K.K., Vijaya, B.P.V.S.S., Kusuma, K.P. and Nagamani, M., 2015. A study of cephalic index and facial index in Visakhapatnam, Andhra Pradesh, India. Int. J. Res. med. Sci., 3: 656-658. https://doi. org/10.5455/2320-6012.ijrms20150324

Lawrence, J.E. and Poole, M.D., 1992. Mid-facial sensation following craniofacial surgery. Br. J. Plast. Surg., 45: 519-522. https://doi.org/10.1016/00071226(92)90146-O

Lieve, M.D.R., Jimmy, H.S., Ingrid, M.G., van Bree H.J., Paul, J. and Loy, A., 2007. Morphometrics and theriology: Homage to Marco Corti. - Hystrix. Italian J. Mammal., 18: 115-136.

Mallon, D.P. and Kingswood, S.C., 2001. Antelopes, Part 4: North Africa the Middle East and Asia. Island Press, 2000 M Street NW, Washington, DC 20036.

Mallon, D.P., 2008. Gazella bennettii: IUCN red list of threatened species, Version 2014.3. International Union for Conservation of Nature.

Monfared, A.L., 2013. Gross anatomical measurements of the head region of the Iranian native cattle Bos taurus and their clinical value for regional anesthesia. Glob. Vet., 10: 219-222.

Mozsary, P.G. and Middleton, R.A., 1983. Microsurgical reconstruction of the infraorbital nerves. J. Oral Maxillofac. Surg., 41: 697-700. https://doi. org/10.1016/0278-2391(83)90183-0

Nickel, R.A., Schummer, A. and Seiferle, E., 1973. Respiratory system in the Viscera of the domestic mammals. Translation and revision by Sack W.C. Vehag Paul Parey, Berlin, pp. 211-279. https://doi. org/10.1007/978-1-4757-6814-5 5

Niven, L.B., Egeland, C.P. and Todd, L.C., 2004. An inter-site comparison of enamel hypoplasia in bison: implications for paleoecology and modelling Late Plains Archaic subsistence. J. Archaeol. Sci., 31: 1783-1794. https://doi.org/10.1016/j. jas.2004.06.001

Olopade, J.O. and Onwuka, S. K., 2005. Morphometric study of the skull of the West African dwarf goat from South West Nigeria. Nigerian Vet. J., 26: 1812. https://doi.org/10.4314/nvj.v26i2.3487

Olopade, J.O. and Onwuka, S.K., 2005. Some aspects of the clinical anatomy of the mandibular and maxillofacial regions of the west african dwarf goat in nigeria. Int. J. Morphol., 23: 33-36. https://doi. org/10.4067/S0717-95022005000100006

Olopade, J.O., Onwuka, S.K., Kwari, H.D. and Oke, B.O., 2006. Caudofrontal depression on the cornual end of the temporal line of the skull of goat breeds in Nigeria. Int. J. Morphol., 24: 349-350. https:// doi.org/10.4067/S0717-95022006000400009

Olopade, J.O., Igado, O.O., Azeez, L.A. and Okandeji, M.E., 2011. Morphometric studies of the eyeball 
and orbital region of the Nigerian local Pig (Sus scrofa). Trop. Vet., 29: 34-40.

Parmar, M.L. and Shrivastava, A.B., 2003a. Anatomy of the skull of chital (Axis axis). XVIII IAVA Convention Souverm and Abstracts, 26-28 ${ }^{\text {th }}$ December 2003. Gujarat Agricultural University, Anand Campus, Anand.

Plug, I., 2014. What bone is that? A guide to the identification of southern African animal bones. Rosslyn Press, Pretoria.

Prince, J.H., Diesem, CD., Eglitis, I. and Ruskell, G.I., 1960: The orbit of dog, cat, horse, cattle, sheep, pig, goat, rabbit. In: Anatomy and histology of the eye and orbit in domestic animals. Blackwell Scientific Publications Ltd., Oxford, pp. 65-69, 99-102, 128130, 154-157, 182-185, 210, 234-237, 260-263.

Prummel, W. and Frisch, H.J., 1986. A guide for distinction of species, sex and body size in bones of sheep and goats. J. Archaeol. Sci., 13: 567-577. https://doi.org/10.1016/0305-4403(86)90041-5

Ramswarup, K., 2011. Gross anatomical studies on the bones of the skull in chital (Axis axis). M.V. Sc. thesis, Rajasthan University of Veterinary and Animal Sciences, Bikaner.

Samuel, O.M., Olopade, J.O., Korzerzer, M.R. and Onwuka, S.K., 2013. Craniometric evaluation of some cranial indices of clinical significance in goats (Capra Hircus) from the Middle-Belt Region of Nigeria - case for population surveillance and ecomigration. Eur. J. Zool. Res., 2: 89-97.

Sarma, K., 2006. Morphological and craniometrical studies on the skull of Kagani goat (Capra hircus) of Jammu region. Int. J. Morphol., 24: 449-455. https:// doi.org/10.4067/S0717-95022006000400025

Shahid, R.U. and Kausar, R., 2005. Comparative gross anatomical studies of the skull of one-humped camel (Camelus dromedarius). Pak. Vet. J., 25: 205-206.

Sheremetyeva, I.N. and Sheremetyev I.S., 2008. Skull variation in the Siberian Roe Deer Capreolus pygargus from the Far East: A revision of the distribution of the subspecies. Eur. J. Wildl. Res., 54: 557-569. https://doi.org/10.1007/s10344-0080180-0

Simoens, P., 2003. Magnetic resonance imaging, computed tomography and crosssectional views of the anatomy of normal nasal cavities and paranasal sinuses in mesaticephalic dogs. Am. J. Vet. Res., 64: 1093-1098. https://doi.org/10.2460/ ajvr.2003.64.1093

Simoens, P., Poels, P. and Lauwers, H., 1994. Morphometric analysis of the foramen magnum in Pekingese dogs. Am. J. Vet. Res., 55: 34-39.

Smuts, M. and Bezuidenhout, A.J., 1987. Anatomy of the dromedary. Clarendon Press, Oxford, UK, pp. 24-47.

Soper, R., 2002. Nyanga: Ancient fields, settlements and agricultural history in Zimbabwe. British Institute in Eastern Africa, London.

Taluja, J.S., Malik, M.R. and Parmar, M.L., 2000. Orbitometry of tiger. Indian Anat., 2: 222.

Uthman, A.T., Al-Rawi, N.H. and Al-Timimi, J.F., 2012. Evaluation of foramen magnum in gender determination using helical CT scanning. Dentomaxillofac. Radiol., 41: 197-202. https://doi. org/10.1259/dmfr/21276789

Von Den Driesch, A., 1976. A guide to the measurement of animal bones from archeological sites. Peabody Museum Bulletin, Harvard University, Massachusetts.

World Association of Veterinary Anatomists, 2012. Nomina anatomica veterinaria, $5^{\text {th }}$ ed. International Committe on Veterinary Gross Anatomical Nomenclature (ICVGAN), World Association of Veterinary Anatomists, Konxville, T.N., USA, pp. 18-23.

Yahaya, A., Olopade, J.O., Kwari, H.D. and Wiam, I.M., 2012. Osteometry of the skull of one-humped camels, Part I: Immature animals. Italian J. Anat. Embryol., 117: 23-33.

Yahaya, A., Olopade, J.O., Kwari, H.D. and Hambali, I.U., 2012. Some aspects of the maxillofacial and mandibular anatomy of camels (Camelus dromedaries) in Nigeria. J. morphol. Sci., 29: 140143.

Yalçin, H. and Kaya, M.A., 2009. Anadolu Yaban Koyunu ve Akkaraman Koyununun Kafa Kemikleri Üzerinde Karşilaştirmali Geometrik Morfometri. Atatürk Üniversitesi Vet. Bil. Derg., 4: 105-116.

Zedda, M., Manca, P., Chisu, V., Gadu, S., Lepore, G., Genovese, A. and Farina, V., 2006. Ancient pompeian dogs: Morphological and morphometric evidence for different canine populations. Anat. Histol. Embryol., 35: 319-324. https://doi. org/10.1111/j.1439-0264.2006.00687.x

Zide, B. and Swift, R., 1998. How to block and tackle the face. Plastic Reconstr. Surg., 101: 840-851. https:// doi.org/10.1097/00006534-199803000-00041 